\title{
KERJASAMA GURU BIMBINGAN DAN KONSELING DENGAN GURU MATEMATIKA DALAM PENGEMBANGANBAKAT AKADEMIK KHUSUS MATEMATIKASISWA KELAS CERDAS ISTIMEWA SEKOLAH MENENGAH ATAS NEGERI 3 PONTIANAK
}

\author{
oleh \\ Hastiani, M.Pd dan Rustam, M.Pd. Kons \\ IKIP PGRI PONTIANAK \\ dedekhasty@yahoo.com
}

\begin{abstract}
ABSTRAK
Masalah umum adalah " Bagaimanakah kerjasama guru bimbingan dan konseling dengan guru matematika dalam pengembangan bakat akademik khusus matematika siswa kelas cerdas istimewa SMA Negeri 3 Pontianak ? Tujuan umum penelitian ini adalah untuk mendapatkan informasi yang jelas tentang “ Kerjasama Guru Bimbingan dan Konseling Dengan Guru Matematika Dalam Pengembangan Bakat Akademik Khusus Matematika Siswa Kelas Cerdas Istimewa SMA Negeri 3 Pontianak". Variabel penelitian ini adalah kerjasama guru bimbingan dan konseling dengan guru matematika dalam pengembangan bakat akademik khusus matematika siswa kelas cerdas istimewa. Metode dalam penelitian ini adalah metode deskriptif bentuk studi survei. Teknik pengumpulan data yang digunakan dalam penelitian ini adalah teknik komunikasi tidak langsung dan teknik komunikasi langsung. Alat pengumpulan data yang digunakan adalah angket dan wawancara menggunakan panduan wawancara. Analisis data dengan teknik perhitungan persentase, secara umum disimpulkan kerjasama guru bimbingan dan konseling dengan guru matematika dalam pengembangan bakat akademik khusus matematika siswa kelas cerdas istimewa SMA Negeri 3 Pontianak terlaksana sangat baik. Saran yang diberikan bagi: (1) Siswa, meningkatkan keaktifan untuk mencari literatur materi matematika, mengikuti les di luar sekolah. (2) Guru bimbingan dan konseling, aktif memberikan layanan informasi yang berkaitan dengan faktor-faktor yang mempengaruhi pengembangan bakat akademik khusus matematika.(3) Guru matematika mengikuti pembinaan kompetensi melalui pelatihan, memahami perbedaan kepribadian siswa sehingga dapat melayani sesuai kebutuhan siswa kelas cerdas istimewa. (4) Kepala Sekolah, mengalokasikan dana sebagai upaya melengkapi sarana dan prasarana untuk pengembangan bakat akademik khusus matematika siswa kelas cerdas istimewa di sekolah.
\end{abstract}

Kata kunci : Kerjasama, Bakat Akademik Khusus Matematika, Siswa Cerdas Istimewa

\section{ABSTRACT}

A common problem is " How can cooperation with teacher guidance and counseling teacher of mathematics in the development of specific academic aptitude math smart grade students of SMA Negeri 3 Pontianak special ? The general objective of this research is to obtain clear information about the " Cooperation Guidance and Counseling Teacher With Math Teacher In Special Academic Talent Development Math Smart Class Outstanding Students of SMA Negeri 3 Pontianak " . The variables of this research is collaboration with teacher guidance and counseling teacher of mathematics in the development of specific academic aptitude math smart grade students special. The method in this study is descriptive survey study form . Data collection techniques used in 
this study is the technique of indirect communication and direct communication techniques . Data collection tool used was a questionnaire and interviews using an interview guide. Analysis of the data with the percentage calculation technique, the general concluded cooperation with teacher guidance and counseling teacher of mathematics in the development of specific academic aptitude math smart grade students of SMA Negeri 3 Pontianak privileged done very well. Suggestions are given for :( 1 ) Students, increase liveliness to find literature math materials, follow lessons outside of school.( 2 ) The teacher guidance and counseling, actively provide information relating to the factors that influence the development of specific academic aptitude mathematics . ( 3 ) The teacher of mathematics follow the coaching competencies through training, so that students understand the differences in personality can serve as needed intelligent privileged class students. (4) Principal, allocate funds as a complementary effort to the development of infrastructure specific academic aptitude math smart grade students in special schools

Key words : Cooperation, SpecialAcademicMathematicsTalent, Special Intelligence

\section{PENDAHULUAN}

Peserta didik yang memiliki kecerdasan istimewa dan menempuh pendidikan khusus, dibimbing untuk mengenalkan dan meningkatkan potensi seperti mengembangkan bakat sesuai dengan kriteria anak cerdas istimewa, sehingga dapat membantu dalam pencapaian prestasi baikprestasi akademik maupun non akademik.Potensi diri yang dimiliki oleh peserta didik diantaranya bakat, merupakan sumber daya diri yang harus dipahami dan ditingkatkan secara tepat.Asrori menyatakan"Bakat

(aptitude) mengandung makna kemampuan bawaan yang merupakan potensi (potential ability) yang masih perlu pengembangan dan latihan lebih lanjut, karena bersifat potensial maka memerlukan pengembangan dan pelatihan secara serius dan sistematis agar dapat terwujud". Bakat bidang matematika termasuk dalam kategori bakat akademik khusus, diantaranya peserta didik mempunyai kemampuan untuk bekerja dalam angka-angka (numeric), logika, dan sejenisnya.

Berkenaan dengan bakat akademik, Asrori (2008:75) menyatakan "Adapun bakat akademik, misalnya mahir dalam bidang angka-angka (numeric), logika, bahasa dan sejenisnya". Bakat akademik khusus matematika hanya tampak dalam diri peserta didik tertentu antara lain kemampuan hitung menghitung, mengukur, berpikir logis, serta menyelesaikan masalah matematika, selain itu memiliki keterampilan mengolah angka-angka.Paparan diatas mengisyaratkan peran penting guru bimbingan dan konseling didunia pendidikan, guru bimbingan dan konseling di sekolah berperan membantu peserta didik agar dapat merasakan manfaat dari pengalamanpengalaman yang mereka dapatkan selama berada di sekolah. Melalui bimbingan peserta didik dapat mencapai perkembangan sosial, pribadi dan akademis.

Perkembangan bakat akademik dipengaruhi oleh faktor yang berasal dari anak sendiri dan faktor lingkungan tempat anak tumbuh dan berkembang. Beberapa faktor yang berasal dari anak diantaranya anak kurang berminat mengembangkan bakat yang dimiliki, minimnya motivasi untuk berprestasi. Faktor lingkungan tempat tumbuh dan berkembang mempunyai peranan penting misalnya, lingkungan keluarga anak tidak dibiasakan berlatih dengan hitung-hitungan atau mengulang kembali materi matematika yang 
dipelajari.Berkenaan dengan faktor mempengaruhi perkembangan bakat khusus temasuk bakat akademik khusus matematika,Asrori

(2008:76)

menyatakan:

Ada sejumlah faktor yang mempengaruhi perkembangan bakat khusus yang secara garis besar dapat dikelompokan menjadi faktor Internal dan Eksternal. Faktor Internal barasal dari dalam diri individu meliputi: minat, motif berprestasi, keberanian mengambil resiko, keuletan dalam menghadapi tantangan, ketagihan atau daya juang dalam mengatasi kesulitan yang timbul. Faktor Eksternal adalah faktor yang berasal dari lingkungan individu tumbuh dan

berkembangmeliputi:kesempata nmaksimal untuk mengembangkan diri, sarana dan prasarana, dukungan dan dorongan orang tua atau keluarga, lingkungan tempat tinggal, serta pola asuh orang tua.

Keberbakatan tidak selalu menjamin sukses pendidikan atau produktivitas dan kreativitas. Rimm dalam Conny Semiawan (2008:208) menyatakan "yang menjadi faktor penentu agar anak berbakat akan menjadi prestasi belajar tinggi (superachievement) atau prestasi belajar kurang (underachievement), tergantung dari rumah, sekolah dan teman sebaya".Peserta didik yang memiliki bakat akademik khusus matematika, jika memperoleh dukungan baik internal maupun eksternal, yakni memiliki minat yang tinggi tehadap bidang matematika,motivasi berprestasi yang tinggi,daya juang tinggi, dan kesempatan maksimal untuk mengembangkan bakat bidang matematika secara optimalmaka bakat tersebut akan menjadi kemampuan unggul dan mencapai prestasi yang menonjol. Keberbakatan tidak selalu menjamin sukses pendidikan atau produktivitas dan kreativitas. Rimm dalam Conny Semiawan (2008:208) menyatakan "yang menjadi faktor penentu agar anak berbakat akan menjadi prestasi belajar tinggi (superachievement) atau prestasi belajar kurang (underachievement), tergantung dari rumah, sekolah dan teman sebaya".

Perkembangan bakat akademik khusus matematika yang tidak mendapatkan dukungan, baik internal maupun eksternal menyebabkan peserta didik menjadi underachiever. Home Gaskill Hutchkin dalam Conny Semiawan (2008:209) menyatakan "yang disebut underachievement anak berbakat adalah kinerja yang secara signifikan berada di bawah potensinya", peserta didik memiliki kemampuan intelektual tinggi, namun prestasi belajar yang dicapai di bawah kemampuan yang dimiliki. Berdasarkan hasil prasurvei, kerjasama guru bimbingan dan konseling dengan guru matematika belum terlaksana secara sinergis seperti,siswa memiliki kemampuan intelektul umumdibawah kategori sangat cerdas atau very superior IQ $>130$ skala Wechslersebagaimana persyaratan yang ditentukan,peserta didik kelascerdas istimewa memiliki nilai matematika dibawah 70, Kriteria Ketuntasan Minimal (KKM) matematika 70, maupun Ilmu Pengetahuan Alam yang mengakibatkan mereka harus mengikuti program remedial.

Berdasarkan pada pemikiran yang telah diuraikan, perlu diadakan penelitian tentang kerjasama antara guru bimbingan dan konseling dengan gurumatematika dalam pengembangan bakat akademik khusus matematika siswa kelas cerdas istimewa SMA Negeri 3 Pontianak untuk memperolehdata empiris, sehingga perlu 
adanya pembuktian antara fenomena yang ada dengan teori.

\section{METODE PENELITIAN}

Hadari Nawawi (2007:65) terdapat beberapa metode yang tepat dalam penelitian ilmiah. Metode tersebut adalah:
a. Metode deskriptif
b. Metode eksperimen
c. Metode historis dan dokumenter
d. Metode filosofis

Adapun metode yang dianggap tepat dalam penelitian ini adalah metode deskriptif. Penggunaan metode ini didasarkan kepada pendapat Hadari Nawawi (2007:67) yang menyatakan"Metode deskriptif dapat diartikansebagai prosedur pemecahan masalah yangdiselidiki menggunakan/melukiskan keadaan subjek/objek penelitian (seorang, lembaga, masyarakat dan lain-lain).

$$
\text { Pada saat sekarang }
$$

berdasarkan fakta-fakta yang tampak /sebagaimana mestinya". Metode ini dipilih karena penelitian yang dilaksanakan bertujuan untuk mengungkap fakta, keadaan, variabel dan fenomena-fenomena yang terjadisaat penelitian berlangsung secara apa adanya di SMA Negeri 3 Pontianak. Hadari Nawawi (2007:68) menyatakan ada banyak bentuk penelitian yang dapat digunakan dalam suatu penelitian, diantara bentuk penelitian yang dimaksud adalah :

$$
\begin{aligned}
& \text { a.Studi survei (survey study) } \\
& \text { b. Studi hubungan } \\
& \text { c.Studi (interrelationships studies) } \\
& \text { (developmental studies) }
\end{aligned}
$$

Dari beberapa bentuk penelitian maka, bentuk yang paling sesuai dengan tujuan yang ingin dicapai dalam penelitian ini adalah survei (Survey Studies).M.Subana dan Sudrajat (2000:27) menyatakan "survei pada umumnya merupakan suatu cara pengumpulan data dari sejumlah unit atau individu dalam jangka waktu yang bersamaan dalam jumlah besar dan luas".

Jadi penelitian survei adalah cara pengumpulan data pada sejumlah sumber data dalam waktu yang bersamaan dengan menggunakan kuesioner dan wawancara terstruktur. Untuk menganalisis data hasil angket menggunakan perhitungan persentase dengan rumus sebagai berikut : M. Ali, $1998: 18$

$\mathrm{X} \%=\frac{\mathrm{n}}{\mathrm{N}} \times 100 \%$

Data hasil wawancara dengan guru bimbingan dan konseling serta guru matematika akandianalisis dan diinterpretasikan secara rasional.

\section{HASIL DAN PEMBAHASAN}

Analisis kuantitatif , tugas yang dilakukan guru bimbingan dan konseling dalam pengembangan bakat akademik khusus matematika untuk indikator pelaksanaan kegiatan dan tindak lanjut $72,19 \%$ telah terlaksana dengan baik. Tugas yang dilakukan guru matematika dalam pengembangan bakat akademik khusus matematika $83,60 \%$ telah terlaksana sangat baik.

Analisis kualitatif,

1. Tugas yang dilakukan guru bimbingan dan konseling dalam pengembangan bakat akademik khusus matematika, memberikan layanan informasi yang berkaitan dengan pengembangan bakat akademik khusus matematika terdiri dari:

a. Pelaksanan kegiatan, melalui layanan informasi tentang:

1) Pengertian anak berbakat akademik khusus matematika

2) Karakteristik anak berbakat akademik khusus matematika

3) Faktor-faktor yang mempengaruhi pengembangan bakat akademik khusus matematika 
4) Hubungan bakat akademik khusus matematika dengan prestasi

5) Implikasi pengembangan bakat akademik khusus matematika terhadap pendidikan

b. Pemberian tindak lanjut, melalui :

1) Tindak lanjut singkat dan segera berupa penguatan dan penugasan kepada siswa

2) Menempatkan dan mengikutsertakan siswa dalam layanan tertentu

3) Memberikan satuan layanan atau pendukung yang baru sebagai pelengkap layanan sebelumnya

2. Tugas yang dilakukan guru matematika dalam pengembangan bakat akademik khusus matematika, meliputi :

a. Memilih dan menggunakan metode mengajar yang tepat

b. Membimbing siswa untuk aktif mengerjakan latihan dan tugas rumah

c. Memberikan tugas yang merangsang untuk diselesaikan siswa

d. Memberikan waktu dan tambahan belajar untuk siswa di sekolah

3. Kegiatan yang dilakukan bersamasama guru bimbingan dan konseling dengan guru matematika dalam pengembangan bakat akademik khusus matematika, meliputi :

a. Perencanaan: Kegiatan menyusun dan mempersiapkan semua yang diperlukan dalam kerjasama guru bimbingan dan konseling dengan guru matematika

b. Pelaksanaan kegiatan: Implementasi kegiatan yang telah direncanakan dan diperlukan dalam kerjasama guru bimbingan dan konseling dengan guru matematika.

c. Evaluasi: Kegiatan yang dilakukan untuk mengetahui keberhasilan kerjasama yang dilakukan guru bimbingan dan konseling dengan guru matematika dalam pengembangan bakat akademik khusus matematika.

d. Analisis evaluasi

Kegiatan yang dilakukan guru bimbingan dan konseling dengan guru matematika untuk mengetahui hasil evaluasi yang dilakukan.

e. Tindak lanjut : Kegiatan bantuan yang dilakukan guru bimbingan dan konseling dengan guru matematika yang beracuan pada hasil analisis

f. Koordinasi, yaitu aktivitas menyesuaikan atau menyelaraskan kegiatan yang akan atau sedang dilaksanakan oleh pihak yang bekerjasama dalam hal ini guru bimbingan dan konseling dengan guru matematika

g. Konsultasi, yaitu kegiatan diskusi tentang suatu kegiatan yang dilakukan antara dua pihak sebagai upaya memberikan pendapat maupun keterangan dengan maksud untuk meningkatkan kualitas pelaksanaan kegiatan.

4. Dukungan dan hambatan yang dihadapi guru bimbingan dan konseling dengan guru matematika dalam pengembangan bakat akademik khusus matematika siswa kelas cerdas istimewa, meliputi :

a. Dukungan internal guru bimbingan dan konseling

1) Kemampuan sebagai teladan dan pemimpin atau orang berpengaruh, di lingkungan sekolah sosok guru bimbingan dan konseling sebagai teladan/model yang dapat memberikan inspirasi bagi siswa untuk berperilaku yang beradab dan efektif baik di lingkungan sekolah maupun di luar lingkungan sekolah. 
2) Altruisme, kesediaan untuk mengorbankan waktu dan tenaga Guru bimbingan dan konseling mendapatkan kepuasan dan rasa senang ketika dapat membantu siswa di sekolah untuk mencapai pengembangan bakat akademik khusus matematika sebagai siswa cerdas istimewa.

3) Tanggung jawab, bentuk tanggung jawab guru bimbingan dan konseling dalam pengembangan bakat akademik khusus matematika siswa kelas cerdas istimewa, melaksanakan tugas melalui layanan informasi serta tindak lanjut karena pengembangan bakat akademik khusus matematika tidak terlepas dari peran guru matematika sehingga guru bimbingan dan konseling melakukan kerjasama dengan guru matematika, tetapi tetap memantau perkembangan kemampuan matematika siswa. Guru bimbingan dan konseling tidak akan membiarkan masalah tanpa penyelesaian.

b. Dukungan eksternal guru bimbingan dan konseling

1) Manajemen bimbingan dan konseling, pengembangan bakat akademik khusus matematika manajemen bimbingan berperan agar siswa kelas cerdas istimewa bertanggung jawab, dapat berprestasi dengan bakat matematika yang dimiliki, mampu menyelesaikan kesulitan yang dihadapi, serta bisa mengakui masalah yang dihadapi dalam mencapai perkembangan bakat akademik khusus matematika yang dimiliki.
2) Manajemen kesiswaan, adanya prinsip dasar dalam manajemen kesiswaan memberikan landasan bagi guru bimbingan dan konseling untuk memperhatikan bahwa siswa bukan hanya sebagai objek melainkan siswa harus diperlakukan sebagai subjek, kondisi siswa yang beragam, siswa akan temotivasi belajar didasari rasa senang, pengembangan potensi siswa menyangkut ranah kognitif, afektif dan psikomotorik.

3) Kode etik bimbingan dan konseling, merupakan pedoman sikap dan tingkah laku terutama dalam pelaksanaan tugas pengembangan bakat akademik khusus matematika.

c. Dukungan internal guru matematika

1) Harapan guru, adanya harapan dari guru agar siswa mencapai pengembangan bakat akademik khusus matematika dengan optimal, maka harapan tersebut akan berpengaruh terhadap sikap dan tingkah laku yang akan ditampilkan dalam cara menyampaikan materi matematika dengan baik.

2) Motivasi, memilih profesi guru karena ingin menyumbangkan tenaga, pikiran bagi siswa agar siswa kelas cerdas istimewa mencapai perkembangan bakat akademik khusus matematika.

d. Dukungan eksternal guru matematika

1) Perkembangan teknologi pendidikan dan tantangan otonomi daerah, adanya perkembangan tenologi pendidikan memberikan 
$\begin{array}{lrr}\begin{array}{l}\text { kontribusi kepada } \\ \text { matematika }\end{array} & \text { untuk }\end{array}$ menggunakan berbagai metode mengajar yang tepat untuk memenuhi kebutuhan anak kelas cerdas istimewa.

2) Superfisi akademik, merupakan bantuan profesional yang mendukung untuk meningkatkan kompetensi/ peningkatan kinerja sebagai guru matematika yang mengajar di kelas cerdas istimewa.

3) Kode etik profesi guru, menjadi acuan bertindak dalam melaksanakan tugas dalam pengembangan bakat akademik khusus matematika.

e. Hambatan internal guru bimbingan dan konseling

1) Kompetensi intelektual, pikiran yang cerdas untuk memahami tingkah laku siswa yang beragam, serta pengetahuan tentang kebutuhan siswa kelas cerdas istimewa

2) Kompetensi komunikasi, jika guru bimbingan dan konseling tidak dapat membina komunikasi yang efektif maka tidak dapat memberikan respon secara baik, positif dan konstruktif keterangan jelas tentang siswa kelas cerdas istimewa tidak didapat secara jelas.

f. Hambatan eksternal guru bimbingan dan konseling

1) Keterbatasan waktu dan tugas guru bimbingan dan konseling, ketidaksesuaian antara waktu yang tersedia dengan tugas yang dimiliki.

2) Keterbatasan sarana pendukung, ruang bimbingan dan konseling yang belum memadai melaksanakan konseling individu dan kelompok.

g. Hambatan internal guru matematika

1) Kemampuan guru matematika menguasai kelas serta bahan ajar, anak cerdas istimewa memiliki kemampuan untuk menerima pelajaran lebih cepat dari siswa lain sehingga guru matematika harus memiliki kemampuan yang lebih baik dari guru pada umumnya.

2) Kemampuan guru mengenali dan memahami kepribadian siswa, perbedaan karakteristik kepribadian setiap siswa sehingga guru matematika harus mengenali dan memahami perbedaan tersebut, agar dapat memberikan perlakuan yang sesuai dengan kepribadian siswa cerdas istimewa.

h. Hambatan eksternal guru matematika

1) Tugas guru matematika, guru matematika yang mengajar dikelas cerdas istimewa juga mengajar di kelas lain.

2) Kondisi fisiologis dan psikologis siswa, kondisi kesehatan, minat serta motivasi yang berbeda sehingga guru matematika harus dapat memenuhi kebutuhan siswa sesuai dengan perbedaan tersebut.

3) Lingkungan sekolah, kondisi lingkungan sekolah yang tidak baik berpengaruh terhadap semangat kerja guru matematika, seperti ruang kerja yang belum tertata rapi.

5. Upaya mengatasi hambatan yang dihadapi guru bimbingan dan konseling dengan guru matematika dalam pengembangan bakat 
akademik khusus matematik, meliputi :

a. Hambatan internal guru bimbingan dan konseling

1) Meningkatkan kemampuan intelektual, mengikuti pelatihan seperti In House Training dan Musyawarah Guru Bimbingan dan Konseling (MGBK) untuk menambah wawasan

2) Meningkatkan kemampuan komunikasi, mendengar secara aktif, memahami pambicaraan yang dikomunikasikan secara tepat, dan memberikan respon secara baik, positif dan konstruktif.

b. Hambatan eksternal guru bimbingan daan konseling

1) Waktu dan tugas guru bimbingan dan konseling, layanan bimbingan dan konseling diintegrasikandengan

kegiatan pengajaran maka perlu pengaturan waktu yang terpadu dengan waktu kegiatan belajar mengajar, melaksanakan pelayanan di luar jam pelajaran setelah pulang sekolah.

2) Sarana dan prasarana, dengan memanfaatkan ruang lain sebagai alternatife untuk melaksanakan pelayanan bimbingan dan konseling seperti : perpustakaan, ruang kelas masing-masing.

c. Hambatan internal guru matematika

1) Meningkatkan kemampuan untuk menguasai kelas serta bahan ajar, mengikuti pelatihan yang dilaksanakan khusus untuk guru-guru yang mengajar di kelas cerdas istimewa selain itu ikut serta dalam kegiatan Musawarah
Guru Mata Pelajaran (MGMP) khusus matematika.

2) Mengenal kepribadian siswa, melakukan identifikasi sebagai upaya untuk mengetahui dan memahami karakter dan kepribadian siswa, melalui tes yang dilaksanakan atas kerjasama dengan tim psikologi.

d. Hambatan eksternal guru matematika

1) Melakukan pengaturan waktu yang terpadu dengan jadwal mengajar dan memberikan waktu tambahan belajar setelah pulang sekolah.

2) Melaksanakan seleksi bagi siswa kelas cerdas istimewa, identifikasi terhadap bakat dan minat siswa terhadap bidang matematika serta seleksi kesehatan melalui surat keterangan dokter.

3) Menciptakan lingkungan sekolah kondusif, melalui berbagai penataan lingkungan baik fisik maupun sosial.

\section{SIMPULAN}

1. Tugas yang dilakukan guru matematika dalam pengembangan bakat akademik khusus matematika terlaksana secara baik, ditunjukan dengan guru matematika menggunakan metode mengajar yang tepat, memberikan bimbingan kepada siswa untuk aktif mengerjakan latihan dan tugas rumah, memberikan tugas yang merangsang untuk diselesaikan siswa serta memberikan waktu tmbahan belajar bagi siswa di sekolah.

2. Kegiatan yang dilakukan bersamasama guru bimbingan dan konseling dengan guru matematika dalam pengembangan bakat akademik khusus matematika, meliputi kegiatan perencanaan, pelaksanaan kegiatan, evaluasi, analisis evaluasi, 
memberikan tindak lanjut, koordinasi serta konsultasi.

3. Dukungan dan hambatan yang dihadapi guru bimbingan dan konseling dalam pengembangan bakat akademik khusus matematika, meliputi dukungan internal dan eksternal. Dukungan internal dari guru bimbingan dan konseling yaitu kemampuan guru bimbingan dan konseling sebagai teladan dan pemimpin atau orang berpengaruh, altruisme, dan tanggung jawab sedangkan dukungan internal guru matematika yaitu adanya harapan guru matematika dan motivasi. Dukungan eksternal guru bimbingan dan konseling yaitu manajemen bimbingan dan konseling, manajemen kesiswaan, dan kode etik bimbingan dan konseling, dukungan eksternal guru matematika yaitu perkembangan teknologi pendidikan dan tantangan otonomi daerah, adanya superfisi akademik, dan kode etik guru. Hambatan internal yang dihadapi guru bimbingan dan konseling yaitu kompetensi intelektual, dan kompetensi komunikasi, hambatan internal yang dihadapi guru matematika yaitu kemampuan guru matematika menguasai kelas dan bahan ajar, kemampuan guru mengenali dan memahami kepribadian siswa. Hambatan eksternal yang dihadapi guru bimbingan dan konseling yaitu keterbatasan waktu dan tugas yang dimiliki guru bimbingan dan konseling serta keterbatasan sarana pendukung, sedangkan hambatan eksternal yang dihadapi guru matematika tugas guru matematika, kondisi fisiologis dan psikologis siswa, serta lingkungan kerja guru matematika.

4. Upaya mengatasi hambatan internal dan eksternal yang dihadapi guru bimbingan dan konseling dengan guru matematika dalam pengembangan bakat akademik khusus matematika, meliputi :

a. Upaya guru bimbingan dan konseling mengatasi hambatan internal melalui ikut serta dalam pelatihan untuk meningkatkan kemampuan intelektual serta meningkatkan kemampuan komunikasi melalui mendengar secara aktif, memahami secara tepat dan memberikan respon dengan baik, positif dan konstrukstif. Hambatan eksternal diatasi melalui pengturan waktu yang terpadu dengan waktu kegiatan belajar dan mengajar, mengambil waktu di luar jam pelajaran akan tetapi pada hari sekolah, sarana dan prasarana dapat melakukan alternatife ruangan misal perpustakaan dan ruang kelas.

b. Upaya guru matematika mengatasi hambtan internal melalui pelatihan serta memahami perbedaan karakteristik siswa.

\section{DAFTAR PUSTAKA}

Ahmadi,Abu dan Joko Tri Prasetyo. (2005). Strategi belajar mengajar untuk fakultas tarbiyah, Bandung : Pustaka setia.

Agustiani, H. (2006). Psikologi Perkembangan, Bandung: Rafika Aditama.

Ali, M .( 1998). Penelitian Kependidikan Prosedur dan Strategi. Bandung : Angkasa.

Aqib, zainal .(2002). Profesionalisme guru dalam pembelajaran. Jakarta: Insan Cendikia.

Arikunto, Suharsimi. (2002). Prosedur Penelitian dan Pendekatan Praktek, Jakarta : Bina Aksara. 
Asrori, M. (2008). Perkembangan Peserta Didik, Pontianak: Untan Press.

Asmara, Husnah.(2002).Aplikasi Statistik Untuk Penelitian, Pontianak: Romeo Grafika.

Asmani, Jamal Ma'mur. (2009). Mencetak Anak Jenius, Yogyakarta : Diva Press

Dariyo, Agoes. (2004). Psikologi Perkembangan Remaja, Jakarta: Ghalia Indonesia.

Depdikbud. (1996). Petunjuk Pengelolaan Bimbingan dan Konseling, Jakarta.

Depdiknas.(2007). Pedoman Penyelenggaraan Pendidikan Untuk Peserta Didik Berkecerdasan Istimewa Program Akselerasi, Jakarta.

Djumarah, Syaiful Bahri. (2002). Guru dan Anak Didik Dalam Interaksi Edukatif, Jakarta: Rineka Cipta.

Esti, Sri .W.D .(2008). Psikologi Pendidikan, Jakarta : Gramedia Widya Sarana

Fatimah, Enung. (2009). Psikologi Perkembangan Peserta Didik, Bandung :Pustaka Setia.

Hornby as, et al. (2000). The Advance Learnes Dictionary of Current Eagh, London : Export Univercity.

Munandar, Utami dkk. (1992). Pengembangan Kreativitas Anak Berbakat, Jakarta : Rineka Cipta.

Semiawan, Conny. (2008). Perspektif Pendidikan Anak Berbakat, Jakarta: Grasindo 